\title{
ÉTICA CRISTÃ X ANDROGINIA (em torno de A Demanda do Santo Graal)
}

Lênia Márcia de M. Mongelli*

SÍNTESE - É bastante notória, em A Demanda do Santo Graal (versão portuguesa de original francês do século XIII), a extraordinária severidade dos tabus sexuais. Para fazer cumprir a exigência de castidade que terá como prêmio o Graal, inventam-se estratégias aterrorizantes, destinadas a servir de exemplum aos vassalos de Artur. Dentre elas, destaca-se a figura demoniaca da Besta Ladrador, monstro configurado como uma espécie de Andrógino. A alegoria dá margem à pergunta que é o núcleo deste artigo: como a Demanda encara o mito da androginia?
ABSTRACT - The extraordinary severity of the sexual taboos is very well-known in A Demanda do Santo Graal (Portuguese version of the french original from XIII century). To obtain the chastity which is demanded and which will be rewarded with the Grail, terrifying strategies are planned, destinated to be exemplum to Arthur's vassals. Among these strategies, is emphasized the devil figure of Besta Ladrador, monster considered a kind of androgynous. The allegory sugests a question which is the center of this essay: how does the Demanda treat the myth of androgyny?

Apesar de texto historicamente localizado, o que poderia ser limitador, A Demanda do Santo Graal é indiscutivelmente polissêmico: sabemos tratar-se do maior monumento literário da ficção medieval portuguesa, escrito originalmente na França por volta daquele turbulento século XIII, copiado em solo luso à época de D. Dinis e girando em torno de temas que se desenvolveram e se firmaram ao longo do Feudalismo, embora remontem a tempos primitivos, anteriores mesmo à era crista. A amplitude dessa perspectiva temporal que a novela abarca faz que ela seja síntese de valores que vão da Escolástica ao folclore, da astrologia à alquimia, do ascetismo cristão ao hedonismo pagão - sem jamais perder de vista a ética das Sagradas Escrituras, referencial dominante. Considerar essa multiplicidade de caminhos e reconhecê-los muitas vezes paradoxalmente entrelaçados permite ao leitor uma visão bastante contundente do apogeu da Baixa Idade Média, cujo espírito é de dualidade e transições.

O que difere essa "demanda" alucinada de um Graal mirífico de qualquer outra que tenha realizado o remoto Perlesvaus, o Peredur dos bretões, o Perceval de Chrétien de Troyes e quantos antecederam a versão aqui encenada por Galaaz é a extrema severidade das condições impostas para se chegar ao Vaso sagrado. Não há a menor complacência para com os cavaleiros de Artur e a misericórdia divina,

- Universidade de São Paulo - USP. 
nos raros casos de perdão, só se manifesta após dolorosíssimos períodos de provação, verdadeiros embates de consciência precedendo o arrependimento e a culpa. Com tal insistência se alerta para o horror ao Pecado, que nem o sono dos pobres vassalos de Camaalot pode ser tranqüilo, povoado de visões e de terriveis prognósticos, a condenar o prevaricador e a fartá-lo do temor de Deus. Os ermitães, incansáveis na lida, enchem os guerreiros de "histórias de proveito e exemplo", lembrando-lhes o abandono das paixões e a dedicação às causas da Igreja. Afinal, o momento histórico era o das Cruzadas e Cristo, o modelo da cristandade enfebrecida de misticismo, às voltas, por outro lado, com o desenvolvimento dos centros urbanos e seus apelos mundanais. ${ }^{1}$

O rigor desses avisos disseminados ao longo do enredo tem destino certo: pregar a ascese cristocêntrica a combatentes ardendo de amor - e amor terreno, carnal, prenhe de sensualidade! - não é tarefa fácil; sabem-no os eremitas, eles mesmos pecadores conversos e guardiães da fé, atentos à avassaladora erupção de Eros. Basta lembrar que todos os cavaleiros da Távola Redonda, de uma ou de outra forma, têm ou tiveram uma "amiga" ou filhos bastardos (nem Artur, pai de Artur, o Pequeno, escapou da "queda"), para se entender a severa proibição de não se levar "dona" nem "donzela" durante a viagem, sob pena de perder o Graal. Sabemos que falham porque só Galaaz, o "puro dos puros", chega a Corberic; e pelo caminho vamos conhecendo a falibilidade de cada um: a paixão de Palamades pela mesma Iseu de Tristão e de Rei Mars; o bastardo que o casto Boorz "plantou" na juventude; a "tentação" de Persival; a impetuosidade de Erec conquistador, etc. A encimá-los, de forma superior e emblemática, Ginevra e Lancelot, punidos por traição e adultério, num confronto de todo insustentável entre o dever (laços vassálicos) e a paixão (amor cortês).

Em suma, e para insistir no paradoxo, é a forte e cuidadosamente encoberta presença do Amor na obra que justifica todos os tabus postos como empecilho para o Graal: não pecar contra a castidade, não desejar a mulher do próximo, não levar amante no trajeto peregrinatório, etc. Denuncia-se por negação, como era praxe nos tratados cristãos que, durante principalmente a Alta Idade Média, procuravam conter os avanços de heresias e a disseminação de crendices populares, tão em voga pelo ano mil. ${ }^{2}$ Para erradicar o Mal, nada melhor do que personificá-lo e torná-lo visível, consoante o gosto bíblico do exemplum: a Demanda realiza-o pela criação fantástica da Besta Ladrador. Antes de passar ao exame desse motivo ancestral - 0 do monstro que aterroriza uma comunidade conspurcada por erros vários - grave-se bem: a existência da Besta está atrelada à do Amor $\mathrm{e}$ foi para assustar namorados empedernidos - responsáveis pelo castigo da desertificação do outrora fértil reino de Logres - que a inventaram, em recorte lapidar do que a Idade Média entendia por "educação pelo terror".

A deformidade da Besta tem, na obra, adjetivação específica: "desassemelhada", o que significa que não se parece senão consigo própria, encarnação de uma abstração, dado extremamente excitante em tempo de nominalismo, quando "a lin-

1 André Vauchez. La espiritualidad del Ocidente Medieval, Madrid, Catedra, 1985.

2 Idem, ibidem. 
guagem era um sinal das coisas absolutamente certo e transparente, pois que se lhes assemelhava. Os nomes eram colocados sobre o que eles designavam". ${ }^{3}$ No caso, o que se designa é o incesto, crime tão mais punido porquanto cada vez mais corriqueiro, quer em sociedades pastoris que se acasalavam no pequeno reduto da família lá pela solidão dos montes, ${ }^{4}$ quer para garantir a hereditariedade dos feudos no seio de poderosas familias. ${ }^{5}$ Eis, em rápida síntese, como nasce a Besta na Demanda: a filha de rei Hipómenes, "fremosa" e "estudada em nigromancia", apaixona-se pelo próprio irmão, que a rejeita; desesperada, isola-se aos pés de uma fonte, onde pensa suicidar-se. É quando lhe aparece o Demo e propõe um pacto: em troca de seu amor, ajuda-la-á a vingar-se do irmão. Pacto feito, Satã atrai $\mathrm{O}$ irmão à fonte e a moça finge-se violentada por ele. $\mathrm{O}$ pai, que passava por perto, dá à filha, horrorizado, o direito de escolher a morte para o irmão inocente. Ela resolve atirá-lo a cães famintos e ele, antes de morrer, lança a maldição: "E aa nacença do que tu trages, parecerá que nom foi de mim, ca nunca de homem nem de molher saiu tam maravilhosa cousa como de ti sairá; que diáboo o fez e diáboo trages e diáboo sairá em semelhança da besta mais desassemelhada que nunca homem viu. E porque a caães me fazees dar, haverá aquela besta dentro em si cães que sempre ladrarã em renembrança e em referimento dos caães a que me tu fazes dar". ${ }^{6}$ Portanto, a caricatura hiperbólica da Besta assenta sobre um rol de distorções gravíssimas aos olhos da moral cristã - a nigromancia, o incesto, o suicídio, o pacto demoníaco e a maldição - a dizer, por espelhamento, dos excessos amorosos que sacodem Camaalot.

Por essa via, observamos que a Demanda é uma obra que se constrói de tensões, de ambivalências, cuja variabilidade (coragem x covardia; impulso x obrigação; lealdade $x$ traição, etc.) apenas encobre a dualidade central: a relação homem/mulher, conflituada por ética castradora e mediada pela metáfora emblemática da Besta. Todos os dramas, físicos e morais, que arrasam os membros da corte arturiana decorrem de o Amor colidir com o Graal, ou os apelos sexuais com a salvação da alma. O que está em jogo é a sexualidade mutilada, cortando pela raiz possibilidades que vão da procriação ao prazer e à realização no Outro. Mais angustiante se torna o projeto porque o Graal, que se oferece como símbolo da totalidade e da completude do espírito, se propõe a homens que não podem encontrálas dentro de si mesmos. Ou melhor, a integração que aqui parece possível é apenas entre o homem e Deus, mas segundo os dogmas de uma Igreja misógina, que exclui a mulher como "lixo terreal", conforme palavras textuais do narrador da Demanda. Não se estranhe que o Galaaz messiânico seja angélico (atravessa incorpoIeamente paredes) e assexuado.

A questão é muito mais polêmica do que parece: se o Graal é o arquétipo de um Absoluto que está em Deus, considere-se que desde o Gênesis (27-28) a unici-

Michel Foucault. As palavras e as coisas, Lisboa, Portugália, 1967, p. 58.

4 Ver Régine Pemoud. A mulher no tempo das catedrais, Lisboa, Gradiva, 1984.

5 Ver Georges Duby. Idade Média, idade dos homens, São Paulo, Companhia das Letras, 1989.

6 A Demanda do Santo Graal, ed. preparada por Augusto Magne, Rio de Janeiro, Imprensa Nacional, 1944, vol.II, p. 299. 
guagem era um sinal das coisas absolutamente certo e transparente, pois que se lhes assemelhava. Os nomes eram colocados sobre o que eles designavam". ${ }^{3}$ No caso, o que se designa é o incesto, crime tão mais punido porquanto cada vez mais corriqueiro, quer em sociedades pastoris que se acasalavam no pequeno reduto da família lá pela solidão dos montes, ${ }^{4}$ quer para garantir a hereditariedade dos feudos no seio de poderosas familias. ${ }^{5}$ Eis, em rápida síntese, como nasce a Besta na Demanda: a filha de rei Hipómenes, "fremosa" e "estudada em nigromancia", apaixona-se pelo próprio irmão, que a rejeita; desesperada, isola-se aos pés de uma fonte, onde pensa suicidar-se. É quando lhe aparece o Demo e propõe um pacto: em troca de seu amor, ajuda-la-á a vingar-se do irmão. Pacto feito, Satã atrai o irmão à fonte e a moça finge-se violentada por ele. $O$ pai, que passava por perto, dá à filha, horrorizado, o direito de escolher a morte para o irmão inocente. Ela resolve atirá-lo a cães famintos e ele, antes de morrer, lança a maldição: "E aa nacença do que tu trages, parecerá que nom foi de mim, ca nunca de homem nem de molher saiu tam maravilhosa cousa como de ti sairá; que diáboo o fez e diáboo trages e diáboo sairá em semelhança da besta mais desassemelhada que nunca homem viu. E porque a caães me fazees dar, haverá aquela besta dentro em si cães que sempre ladrarã em renembrança e em referimento dos caães a que me tu fazes dar". ${ }^{6}$ Portanto, a caricatura hiperbólica da Besta assenta sobre um rol de distorções gravíssimas aos olhos da moral cristã - a nigromancia, o incesto, o suicídio, 0 pacto demoníaco e a maldição - a dizer, por espelhamento, dos excessos amorosos que sacodem Camaalot.

Por essa via, observamos que a Demanda é uma obra que se constrói de tensões, de ambivalências, cuja variabilidade (coragem x covardia; impulso x obrigação; lealdade x traição, etc.) apenas encobre a dualidade central: a relação homem/mulher, conflituada por ética castradora e mediada pela metáfora emblemática da Besta. Todos os dramas, físicos e morais, que arrasam os membros da corte arturiana decorrem de o Amor colidir com o Graal, ou os apelos sexuais com a salvação da alma. O que está em jogo é a sexualidade mutilada, cortando pela raiz possibilidades que vão da procriação ao prazer e à realização no Outro. Mais angustiante se torna o projeto porque o Graal, que se oferece como símbolo da totalidade e da completude do espirito, se propõe a homens que não podem encontrálas dentro de si mesmos. Ou melhor, a integração que aqui parece possivel é apenas entre o homem e Deus, mas segundo os dogmas de uma Igreja misógina, que exclui a mulher como "lixo terreal", conforme palavras textuais do narrador da $\mathrm{De}$ manda. Não se estranhe que o Galaaz messiânico seja angélico (atravessa incorporeamente paredes) e assexuado.

A questão é muito mais polêmica do que parece: se o Graal é o arquétipo de um Absoluto que está em Deus, considere-se que desde o Gênesis (27-28) a unici-

3 Michel Foucault. As palavras e as coisas, Lisboa, Portugália, 1967, p. 58.

4 Ver Régine Pernoud. A mulher no tempo das catedrais, Lisboa, Gradiva, 1984.

5 Ver Georges Duby. Idade Média, idade dos homens, São Paulo, Companhia das Letras, 1989.

6 A Demanda do Santo Graal, ed. preparada por Augusto Magne, Rio de Janeiro, Imprensa Nacional, 1944, vol.II, p. 299. 
dade divina implica a junção de contrários, cunhada por Nicolau de Cusa como "coincidentia oppositorum":" "Deus criou o homem à sua imagem; criou-o à imagem de Deus, criou o homem e a mulher. Deus os abençoou: 'Frutificai, disse ele, e multiplicai-vos'." Deixando de lado as numerosíssimas discussões que estes versículos do capítulo I suscitaram, inclusive porque só no capitulo II é criada Eva da costela de Adão, a gerar o mito judeu-cristão da superioridade masculina, ${ }^{8}$ homem/mulher, aqui, parecem fazer parte de um único Ser, total, indivisivel, primitivo, anterior à cisão entre luz e trevas, quente e frio, dia e noite, água e terra, etc., surgida com a Criação. Quer se chame Deus, Adam Kadmon como na Cabala, Homem Primordial, Shiva-Shakti como no tantrismo hindu, ou Homem Zodiacal - o substrato dessas crenças características e herdadas de sociedades primitivas é a figura do Andrógino, que "pode ser definida como o Um que contém o Dois, a saber, o masculino (andro) e o feminino (gyne) $)^{\prime \prime}{ }^{9}$ Não confundir, portanto, com bissexualidade nem com hermafroditismo: "O arquétipo da androginia aparece em nós como um senso inato da unidade cósmica primordial, ou seja, a unicidade ou inteireza da androginia antecede qualquer separação. A psique humana é testemunha dessa unidade primordial e é, portanto, o meio através do qual podemos obter certa percepção da totalidade que inspira espanto e maravilha". ${ }^{10}$ Todas as dualidades que angustiam o Homem - e que na Demanda estão profundamente agudizadas - conduzem ao esforço de reintegrar dois em um, como era no tempo mítico das Origens ou da Idade do Ouro. $\mathrm{E}$ para retomar o tema que nos interessa, arremate-se: um par, masculino/feminino, homem/mulher, serve como expressão simbólica do poder energético subjacente a todas as outras polaridades. A ordem não importa pois, como princípios criadores, um não é válido sem o outro". ${ }^{11}$

Eis uma questão chave na Demanda: a essência do Amor, sob esse ângulo, seria andrógina, enquanto movimento em direção ao Outro, na maioria das vezes incontrolável, como o que parece "empurrar" o contrito e culpado Lancelot no rumo de sua Ginevra, macho e fêmea inconscientemente às voltas com um protótipo original. Já sabemos, por René Nelli e, mais recentemente, por Georges Duby, o quanto a questão da sexualidade tem interessado aos estudiosos da lírica trovadoresca, atraídos pela estranha relação entre .0 trovador ardente e apaixonado por uma dama sempre distante e inacessivel, como se a existência real dela fosse muito mais psíquica do que física. E a Demanda, com sua perspectiva ortodoxamente paulina, a pregar contra a tentação, opta por interditar veementemente aproximações indesejadas, que colocam em risco a procura "assexuada" do Graal. A privação da Carne, a produzir tamanha "confusão de juizos" nos cavaleiros, fala pela unilateralidade a que se obrigou sua condição humana, tornando a altíssima meta impossível $e_{1}$ até mesmo, cruel. Como conseguiriam ser parcialmente perfeitos?

7 Mircea Eliade. Mefistofeles y el Androgino, Barcelona, Labor/Ômega, 1984, p. 101.

8 Ao leitor interessado nessas exegeses, consultar June Singer, Androginia - Rumo a uma nova teoria da sexualidade, São Paulo: Cultrix/Pensamento, 1990, principalmente o capitulo "O Éden revisto: o "Nós" divino que criou pessoas".

10 Idem, ibidem. (O grifo è meu)

11 Idem, ibidem. 
Essa é a maior de todas as contradições com que digladia a Demanda, ecoando a extraordinária tensão instalada no Ocidente a partir das reformas gregorianas.

Tão claros a obra pretende os limites entre as fronteiras do Bem e do $\mathrm{Mal}$, que a Besta Ladrador sempre aparece contraponteada pelo Cervo Branco acompanhado de quatro leões, os quais se transmutarão mais tarde no próprio Cristo e seus quatro evangelistas. Se tivermos presentes certas teorias junguianas sobre a integralidade unitária de Deus, cuja essência não exclui a parcela demoniaca - "O Beemonte e o Leviatã representam a concupiscência primordial do ser. Deus revela seu próprio lado sombrio e, já que o homem participa de Deus, fundamento de sua existência, ele deve compartilhar igualmente de Sua escuridão" ${ }^{12}$ - vemos que a Demanda trabalha em sentido contrário: o reino do Senhor da Luz, ou do Cervo Branco, há de massacrar o do Príncipe das Trevas, ou da Besta Ladrador, conforme atestam cenas como a apocalíptica vitónia de Palamades sobre o monstro ou a destruição do "Castel Felon". Impensável qualquer laço de consangüinidade entre Deus e o Diabo, como Mircea Eliade detectou em certa teologia iraniana ou em mitos arcaicos do folclore religioso do sudeste europeu. ${ }^{13}$

A Igreja que a Demanda representa é aquela dos fanáticos Cruzados, que não medem esforços para chegar a Jerusalém, aquela que pune as aberrações com as chamas da fogueira (Ginevra não aparece, em sonhos, a Lancelot, ardendo no Inferno?), aquela que jamais aceitaria a relação entre os sexos como um elo obscuro de androginia. No universo asséptico da Demanda, todos os vícios devem ser denunciados, o que se configura função metonímica da Besta Ladrador, uma espécie de Andrógino condenado pela deformação demoníaca. Observe-se a junção do substantivo feminino ("Besta") com o adjetivo uniforme ("ladrador"), conforme o português arcaico considerava os adjetivos terminados em or: ${ }^{14}$ a instigante aproximação de macho e fêmea parece corroborar a natureza ambígua da Besta. Sua disforme gravidez, a carregar dentro de si cães que ladram sem parar, como se o princípio feminino tivesse encontrado no interior de si próprio o masculino, sugere uma cópula de "autofertilização", que June Singer atesta ser matéria de vários textos sobre Yoga Kundalini. ${ }^{15}$ Talvez fosse o terror diante dessa Visão demoníaca, que Jung chamaria de mysterium coniunctionis, que levou Ivam, o Bastardo, a prometer a Galaaz: " $E$ bem vos digo que nom quedarei ataa que saiba a verdade, se é coisa que eu possa acalçar". ${ }^{16}$

Que "coisa" seria essa, que parece vedada à razão humana? Por que os cavaleiros empregam metade da vida demandando-a? Não sabem todos que o Graal está reservado para Galaaz, o eleito, motivo mais que suficiente para desistir? Se não o fazem, não seria porque procuram outra das "cousas escondidas" que inflacionam o texto com mirabilia? A preponderância que a Besta Ladrador adquire so-

12 Edward F. Edinger. Ego e Arquétipo, São Paulo: Cultrix/Pensamento, s. d., p. 135.

13 Op. cit., p. 104 e ss.

14 Podia dizer-se indiferentemente um ou ua pastor, como atesta Ismael de Lima Coutinho, Gramática Histórica, $6^{2}$ ed., Rio de Janeiro: Livraria Acadêmica, 1966, p. 66 e 234.

Op. cit., p. 143.

DSG, vol. I, p. 132. 
bre qualquer aventura não permite pensar que os vassalos de Artur estão à cata de si mesmos, ansiosos por completar-se, amputados que foram no cerne de sua inteireza? Como afirma Duby, por razões principalmente politico-sociais, "o casamento não é o lugar do que se define então como o amor ${ }^{\prime 17}$ (comprova-o o triângulo Lancelot/Ginevra/Artur); o ermitão previne: quem levar mulher consigo, "fará pecado mortal" $;^{18}$ em sendo assim, como recuperar a androginia arquetípica ideal, cujo modelo é Deus, que na Demanda se faz representar por Cristo, faceta da sagrada polaridade divino-humana? A busca do Graal apenas mascara o impasse, que a Besta Ladrador metaforiza mas não desfaz.

17 Georges Duby, op. cit., p. 36.

18 DSG, vol. I, p. 76. 